\title{
Multifractal Detrended Fluctuation Analysis in Examining Surface Properties of the Gas-Sensing Metal-Containing Polyacrylonitrile
}

\author{
Nina Konstantinovna Plugotarenko ${ }^{1}$, Tatiana Valerjevna Semenistaya ${ }^{1}$ \& Viktor Vladimirovich Petrov ${ }^{1}$ \\ ${ }^{1}$ Southern Federal University, Russia \\ Correspondence: Tatiana Valerjevna Semenistaya, Southern Federal University, Russia. Tel: 7-863-437-1624. \\ E-mail: semenistayatv@sfedu.ru
}

Received: April 24, 2015

Accepted: May 30, 2015

Online Published: September 30, 2015

doi:10.5539/mas.v9n11p213

URL: http://dx.doi.org/10.5539/mas.v9n11p213

\begin{abstract}
A possibility of applying the multifractal detrended fluctuation analysis (MF-DFA) to the investigation of the gas-sensitivity dependence on the thin-films surface morphology formed using different technological parameters of annealing has been studied. Methods of analyzing the dynamics of complex systems are modified so as to investigate the structure of the metal-containing polyacrylonitrile (PAN) thin films. The long-range power-law correlation in structure of the studied film surface has been studied. The analysis have showed that the time-temperature annealing modes increasing brings to the Hurst parameter value increasing that points to a long-range power-law correlation in structure of the studied film surface.
\end{abstract}

Keywords: atomic force microscopy, IR- pyrolysis, multifractal detrended fluctuation analysis, Hurst index, organic electronics, polyacrylonitrile, self-organization theory, thin film

\section{Introduction}

Room temperature gas sensing applications have drawn considerable attention to the electroconducting polymer organic materials (Li, Wan et al., 2012, Lange et al., 2008, Yakhmi et al., 2012). As a family of materials, conducting polymers have attracted interest in their applications due to their special properties (e.g., tailoring electronic properties by the molecular structure, controllable electrical conductivity, nanostructured shapes (films, nanowires, and NPs), and low-cost but high-yield synthesis (Li, Wan et al., 2012).

Lange $U$. focused on applications of conducting polymers as transducers and includes usual optical (fluorescence, SPR, etc.) and electrical (conductometric, amperometric, potentiometric, etc.) transducing techniques as well as organic chemosensitive semiconductor devices (Lange et al., 2008). The report about conducting polymers that show almost no conductivity in the neutral (uncharged) state and their intrinsic conductivity results from the formation of charge carriers upon oxidizing (p-doping) or reducing (n-doping) their conjugated backbone.

Dawidczyk, T.J. distinguished the organic semiconductors that have the property that their conductivity can increase markedly on the application of voltage, electromagnetic radiation, or heat (Dawidczyk et al., 2013). The change in conductivity possible for that kind of organic materials is the product of the charge density induced by the energetic input multiplied by the mobilities of the charges under electric fields.

Yakhmi, J.V. studied the conducting polymers with conjugated chain structures that are characterized by repeated units in which atomic valence is not satisfied by covalent bonds (Yakhmi et al., 2012). The peculiarity of that kind of organic materials are $\pi$-electrons de-localized over large segments of the polymer chain, which is responsible for the electronic properties of the conjugated polymers.

The heat-treated PAN $\left(-\left[\mathrm{CH}_{2}-\mathrm{CH}(\mathrm{CN})\right]_{\mathrm{n}}-\right)$ is an organic semiconductor and a conjugated polymer. PAN can be converted into semiconductive or conductive states through chemical reactions under annealing or pyrolysis without changing its basic structure (Semenistaya et al., 2013, Petrov et al., 2013, Semenistaya et al., 2015). Under the pyrolysis proceeding at temperatures higher than $300{ }^{\circ} \mathrm{C}$, PAN is transformed into a polymer with a cyclic structure, containing the conjugated double bonds (Semenistaya et al., 2013). Due to the $\pi$-orbital overlap of the neighboring molecules of the conjugated structure, the $\pi$-electrons are de-localized along the entire chain, which provides semiconducting properties of PAN polymer (Wu et al., 1986, Sokół et al., 1987). The method of pyrolysis in vacuum enables to manufacture films with a developed surface morphology and provides uniform distribution of modifying additives in a film. 
The use of heat-treated PAN is advantageous because of its ability to turn into a semiconductor material and can be applied in chemiresistive sensors as they are very simple and can be fabricated through cheap and convenient processes. The nitrogen dioxide sensors based on the $\mathrm{Cu}$-containing PAN thin films were tested to have relatively high sensitivity and rather fast response (Korolev et al., 2008, Makeeva et al., 2011). The Ag-containing PAN thin films revealed their sensitivity to chlorine $\mathrm{Cl}_{2}$ (Semenistaya et al., 2013).

Gas-sensing ability of metal-containing PAN film material is complex owing to the numerous molecular and intermolecular interactions during forming the structure that controlling it spatial and temporal variability. The problem is to choose the appropriate technological parameters to form the structure of best sensing properties. In order to examine how the annealing affects the structural and electric properties of the PAN-based materials we need the scaling characteristics of surface properties.

This study aim is at better understanding the gas-sensitivity of metal-containing PAN films, which were fabricated by using different temperature and time modes of thermal treatment of metal-PAN composite. We want to form the theory predicting the gas sensitivity properties of the metalorganic films from surface morphology aspect.

The film surface images received by means of microscopy can serve as a starting point for the analysis by methods of nonlinear dynamics and the information theory (Vikhrov et al., 2005, Bodyagin et al., 1997, Mursalov et al., 2000, Vikhrov et al., 2012, Avacheva et al., 2008). The processes in solid-state formation are characterized by the basic features of self-organizing systems (Vikhrov et al., 2005). Self-organization theory with concept of deterministic chaos is the approach, which makes it possible to simulate the structure of amorphous semiconductors and control the technologies of it fabrication. Vikhrov S.P. suggested a new approach of describing the formation processes of disordered structures in order to have an efficient method for diagnostics of surface structure using information theory and a method for determining the degree of ordering of the materials' structure (Vikhrov et al., 2012). Vikhrov S.P. showed the ability of the methods to reveal change of structure under influence of technology parameters that is impossible to make by traditional methods (Vikhrov et al., 2012, Avacheva et al., 2008).

We regard the metal-containing PAN thin films as disordered material - nonlinear self-organizing system so we use the MF-DFA when analyzing the material's structure to make it possible to filter a signal disordered by noise and reveal the characteristic structure.

The MF-DFA is widely applied in various areas of the data analysis (Kantelhardt et al., 2001, Kantelhardt et al., 2002, Movahed et al., 2006). The MF-DFA has been introduced to study the long range correlations in fluctuations when a trend is present. In this work the MF-DFA technique is used for the determination of multifractal scaling properties of the metal-containing PAN thin films to develop a new method for diagnostics of gas-sensitive layers.

\section{Method}

To form the films the following components were used: PAN (Aldrich 181315) as a conductive polymer matrix, copper chloride (II) $\mathrm{CuCl}_{2}$ or silver nitrate (I) $\mathrm{AgNO}_{3}$ as a modifying additive to increase the selectivity and adsorption activity of the films, dimethylformamide (DMF) as a solvent. The initial solution was prepared by dissolving the modifying additive and PAN in DMF. The organic polymer contributes to disaggregating the small nanoparticles of the modifying additive.

The film forming proceeding was carried out in several steps in the chamber of IR-radiation and the thermal annealing chamber.

The Cu-containing PAN films were fabricated by three methods. The initial solution concentrations of the modifying additive were $1.0 \mathrm{wt} . \%, 2.0 \mathrm{wt}$. $\%$ and $3.0 \mathrm{wt}$. $\%$.

The first fabrication method is the pyrolysis method under the influence of incoherent IR-radiation under inert atmosphere conditions on the developed technology (Al-Hadrami et al., 2008). The film samples were dried at $90{ }^{\circ} \mathrm{C}$ for 30 minutes. The radiation intensity of the IR-annealing corresponds to temperatures of $600{ }^{\circ} \mathrm{C}$ and $700{ }^{\circ} \mathrm{C}$ during a 15 -minute period.

The second method is the thermal annealing in air atmosphere at $200{ }^{\circ} \mathrm{C}$ during a 840 -minute period (Lu et al., 2012).

The third method is the pyrolysis method under the influence of incoherent IR-radiation under low vacuum conditions ( $\mathrm{Lu}$ et al., 2012). The radiation intensity of IR-annealing corresponds to $200{ }^{\circ} \mathrm{C}$ and $500{ }^{\circ} \mathrm{C}$ temperatures during a 10-minute time period. 
The Ag-containing PAN films were formed under the influence of incoherent IR-radiation under low vacuum conditions (Semenistaya et al., 2013). The initial solution concentration of the modifying additive was $1.5 \mathrm{wt} . \%$. One of the two studied film samples was dried at $160^{\circ} \mathrm{C}$ for 30 minutes. The radiation intensity at the first stage of IR-annealing corresponds to temperature of $300^{\circ} \mathrm{C}$ during a 5-minute time period, and the intensity of radiation at the second stage of the IR-annealing corresponds to $500^{\circ} \mathrm{C}$ temperature during a 20 -minute period.

In order to choose the technological parameters to provide the best gas-sensitivity the investigation of the surface properties of the metal-containing PAN thin films was fulfilled.

The gas sensitivity ( $S$ ) was defined as the following ratio $S=\left(R_{0}-R_{g}\right) / R_{0}$, when $R_{0}>R_{g}$, where $R_{0}$ is the resistance in air, $R_{g}$ is the resistance in the atmosphere of the detected gas (Semenistaya et al., 2015).

The film surface morphology was observed by atomic force microscopy (AFM) using scanning probe microscope Solver P47 Pro (NT-MDT). The $5 \times 5 \mu^{2}$ area AFM-images of the films were processed with Image Analysis program.

The MF-DFA technique was used for the height distribution of rough surface profiles analysis.

The Hurst exponent $(\mathrm{H})$ that characterizes the type of self-affinity was used for the MF-DFA procedure analysis.

To estimate the Hurst exponent for self-affine time series the detrended fluctuation analysis (DFA) was used (Kantelhardt et al., 2001, Kantelhardt et al., 2008). In this approach, the cumulative row for the original data points $x(t)$ is performed and divided into $\mathrm{N}$ segments of equal lengths $s$. The fluctuation function $F(s)$ for each segment $y(t)$ is calculated as:

$$
F^{2}(s)=\frac{1}{s} \sum_{i=1}^{x}\left(y(t)-Y_{m}(t)\right)^{2},
$$

where $Y_{m}(t)$ - the local $m$ - polynomial trend within the segment.

The function $F(s)$ is averaged over all segments $y(t)$. This procedure is repeated for various values of segment size to obtain the $F(s)$ dependance in the wide range of $s$ parameter. The $F(s)$ function increases with $s$ growth and a linear relation on the $\log F(s)-\log s$ plot indicates the scale invariance for processes with fractal properties:

$$
F(s) \infty s^{H}
$$

The multifractal process properties were investigated by the MF-DFA (Pavlov et al., 2007, Kantelhardt et al., 2008, Oswiecimka et al., 2006). The MF-DFA procedure is based on the identification the $q$-dependance of the fluctuation functions $F_{\mathrm{q}}(s)$ :

$$
F_{q}(s)=\left\{\frac{1}{N} \sum_{i=1}^{N}\left[F^{2}(s)\right]^{\frac{q}{2}}\right\}^{\frac{1}{q}}
$$

that is defined via taking $q$ degree of (1) with subsequent average over all segments. The $F_{q}(s)$ dependence is defined via the variance of the time series $s$ at the fixed $q$ indicator and is represented in double logarithmic coordinates. In case the multifractal set shows long-term correlations, the fluctuation function $F_{\mathrm{q}}(s)$ is characterised by the power dependence:

$$
F_{q}(s) \infty s^{h(q)}
$$

with the generalized Hurst exponent $h(q)$ function. The generalized Hurst exponent $h(q)$ is equal the Hurst index $H$ and its values are independent of $q$ if the series is mono-fractal and the fluctuation function $F_{\mathrm{q}}(s)$ is the same for all segments. For multifractal series, $h(q)$ is nonlinear function and its values depend on $q$ : the value for $h$ at positive $q$ corresponds to the fluctuation functions $\mathrm{F}_{\mathrm{q}}(\mathrm{s})$ with the segments showing big deviations of $F^{2}(s)$, and at negative $q$ - to the segments with small dispersions of $F^{2}(s)$. So at negative $q$ values the generalized Hurst exponent $h(q)$ depicts segments with low fluctuation, and at positive $q$ values - strong fluctuation.

The parameter $H, O H 1$ is called the Hurst index, represents the self-similarity degree and the type of self-affinity. Along with this property, the Hurst exponent characterizes a long-term correlation measure of stochastic process.

In work (Pavlov et al., 2007) it is noted that one of shortcomings of a multifractal spectrum estimation is that the upper envelope of the veritable spectrum is estimated. It will lead to an over-estimation of numerical results as at the $f(\alpha)$ veritable spectrum, the envelope includes a set of false points. Therefore, there is a need of carrying out additional researches for confirmation of existence of multifractal properties for small length series.

In this paper, we use the free MATLAB software to synthesize fluctuation functions with the Hurst index $H$ through numerical simulations by MF-DFA procedure. 


\section{Results}

In the work, the AFM images of the metal-containing PAN film surfaces formed under various time-temperature IR-annealing modes from initial solutions with different concentration of modifying additives were analyzed and are shown in Fig. 1-3. The wide range of sizes and shapes of the film surface morphology in dependence on the technological parameters of its fabrication are evident (table 1). The observed variations of the height distribution of rough surface profiles were then unfolded to generate the fluctuation series, which were subsequently analyzed via the MF-DFA technique. For references the Hurst index in comparison with whitenoise time series and a number of data characterizing monofractal series were given.

In order to reveal the connection between structure and gas-sensing properties the metal-containing PAN films with different modifying additives $\left(\mathrm{AgNO}_{3}\right.$ and $\left.\mathrm{CuCl}_{2}\right)$ fabricated using the IR-pyrolysis and the thermal annealing methods were studied.

As observed from Fig. 1 the Cu-containing PAN film surface is not uniform and the Hurst index value is father high. There is an evident double kink on the multifractal spectrum that testifies to existence of the three local scopes with different Hurst index values.

Figure 2 depicts the practically homogeneous surface of the $\mathrm{Cu}$-containing PAN film that were fabricated by IR-pyrolysis under inert atmosphere conditions. The height distribution function is near-normal, there is a weak kink on the multifractal spectrum.

A regular dense structure surface is observed on AFM-image of the Ag-containing PAN film (Fig. 3). The height distribution function has a plateau and the multifractal spectrum has a kink.

Table 1. The values of the Hurst index $(\mathrm{H})$, obtained by MF-DFA, gas sensitivity (S) and technological parameters of the Ag-containing PAN films and the $\mathrm{Cu}$-containing PAN films

\begin{tabular}{cccccc}
\hline № & Sample & $\mathrm{H}$ & $\begin{array}{c}\text { S, r.u. } \\
\left(\mathrm{CNO}_{2}=146 \mathrm{ppm}\right)\end{array}$ & Film fabrication method $^{*}$ & $\omega(\mathrm{Me})$, wt. \% \\
\hline 1 & PAN/Cu & 0.45 & 0.15 & 1 & 1.0 \\
2 & PAN/Cu & 0.72 & 0.35 & 2 & 1.0 \\
3 & PAN/Cu & 0.73 & 0.49 & 2 & 2.0 \\
4 & PAN/Cu & 0.76 & 0.18 & 2 & 3.0 \\
5 & PAN/Cu & 0.61 & 0.18 & 3 & 3.0 \\
6 & PAN/Cu & 0.75 & 0.12 & 4 & 3.0 \\
7 & PAN/Ag & 0.56 & 0.35 & 5 & 1.5 \\
8 & PAN/Ag & 0.59 & 0.35 & 6 & 1.5 \\
\hline
\end{tabular}

${ }^{*} 1$ - IR-pyrolysis under low vacuum conditions: $\mathrm{T}_{\mathrm{IR} 1}=200^{\circ} \mathrm{C}, \mathrm{t}_{\mathrm{IR} 1}=10 \mathrm{~min} ., \mathrm{T}_{\mathrm{IR} 2}=500{ }^{\circ} \mathrm{C}, \mathrm{t}_{\mathrm{IR} 2}=10 \mathrm{~min}$.;

2 - thermal annealing: $\mathrm{T}_{\text {annealing }}=200^{\circ} \mathrm{C}$, $\mathrm{t}_{\text {annealing }}=840 \mathrm{~min}$.;

3 - IR- pyrolysis under inert atmosphere conditions: $\mathrm{T}_{\mathrm{IR} 1}=600^{\circ} \mathrm{C}, \mathrm{t}_{\mathrm{IR} 1}=15 \mathrm{~min}$.;

4 - IR- pyrolysis under inert atmosphere conditions: $\mathrm{T}_{\mathrm{IR} 1}=700^{\circ} \mathrm{C}, \mathrm{t}_{\mathrm{IR} 1}=15 \mathrm{~min}$.;

5 - IR- pyrolysis under low vacuum conditions: $\mathrm{T}_{\mathrm{IR} 1}=300^{\circ} \mathrm{C}, \mathrm{t}_{\mathrm{IR} 1}=5 \mathrm{~min}$.; $\mathrm{T}_{\mathrm{IR} 2}=500{ }^{\circ} \mathrm{C}, \mathrm{t}_{\mathrm{IR} 2}=20 \mathrm{~min}$;

6 - IR- pyrolysis under low vacuum conditions: $\mathrm{T}_{\text {drying }}=160^{\circ} \mathrm{C}$, $\mathrm{t}_{\text {drying }}=30$ min.; $\mathrm{T}_{\mathrm{IR} 1}=300^{\circ} \mathrm{C}, \mathrm{t}_{\mathrm{IR} 1}=5 \mathrm{~min}$; $\mathrm{T}_{\mathrm{IR} 2}=500^{\circ} \mathrm{C}, \mathrm{t}_{\mathrm{IR} 2}=20 \mathrm{~min}$.

\section{Discussion}

The multifractal series data have local fluctuations with two minimum and two maximum magnitudes unlike a monofractal type of scaling. Lack of fluctuations with minimum and maximum indicates a trend towards monofractal behavior. The absence of fluctuations with extreme large and small magnitudes results in a normal distribution for the monofractal time series where the variation is described by the second order statistical moment (Ihlen, 2012).

In the multifractal time series local fluctuations are extreme large magnitude for segments within the time periods of large fluctuations and extreme small magnitude limit for segments within the time periods of small fluctuations. 
a

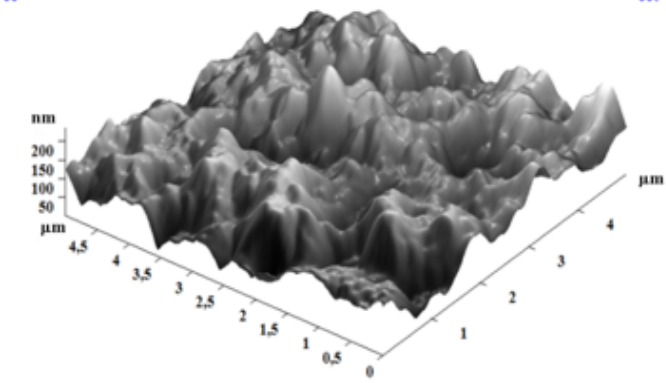

$\mathrm{c}$

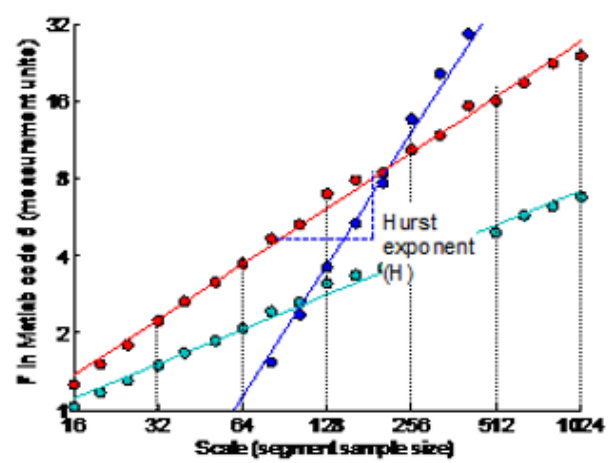

b

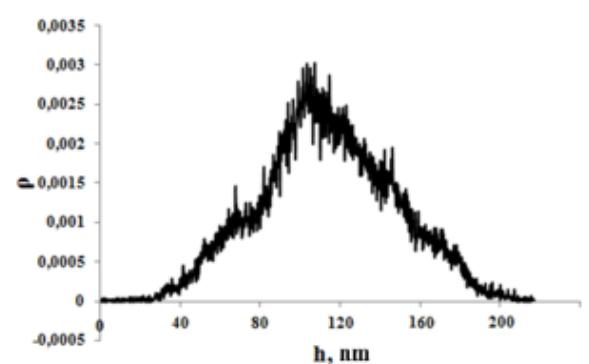

d

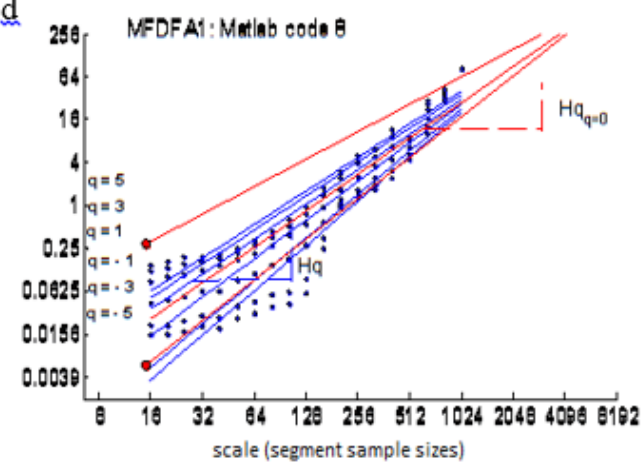

Figure 1. The Cu-containing PAN film. Technological parameters of fabrication: $\omega(\mathrm{Cu})=1.0 \mathrm{wt} . \%, \mathrm{~T}_{\text {anneal }}=$ $200^{\circ} \mathrm{C}, \mathrm{t}_{\text {annael }}=840$ minutes: a) AFM-image (three-dimensional model); b) height distribution function; $\mathrm{c}$ ) the local Hurst exponent (monofractal series - a red line, white noise - a green line, the studied series - a blue line);

d) a multifractal spectrum (a function for the local Hurst exponent estimation)
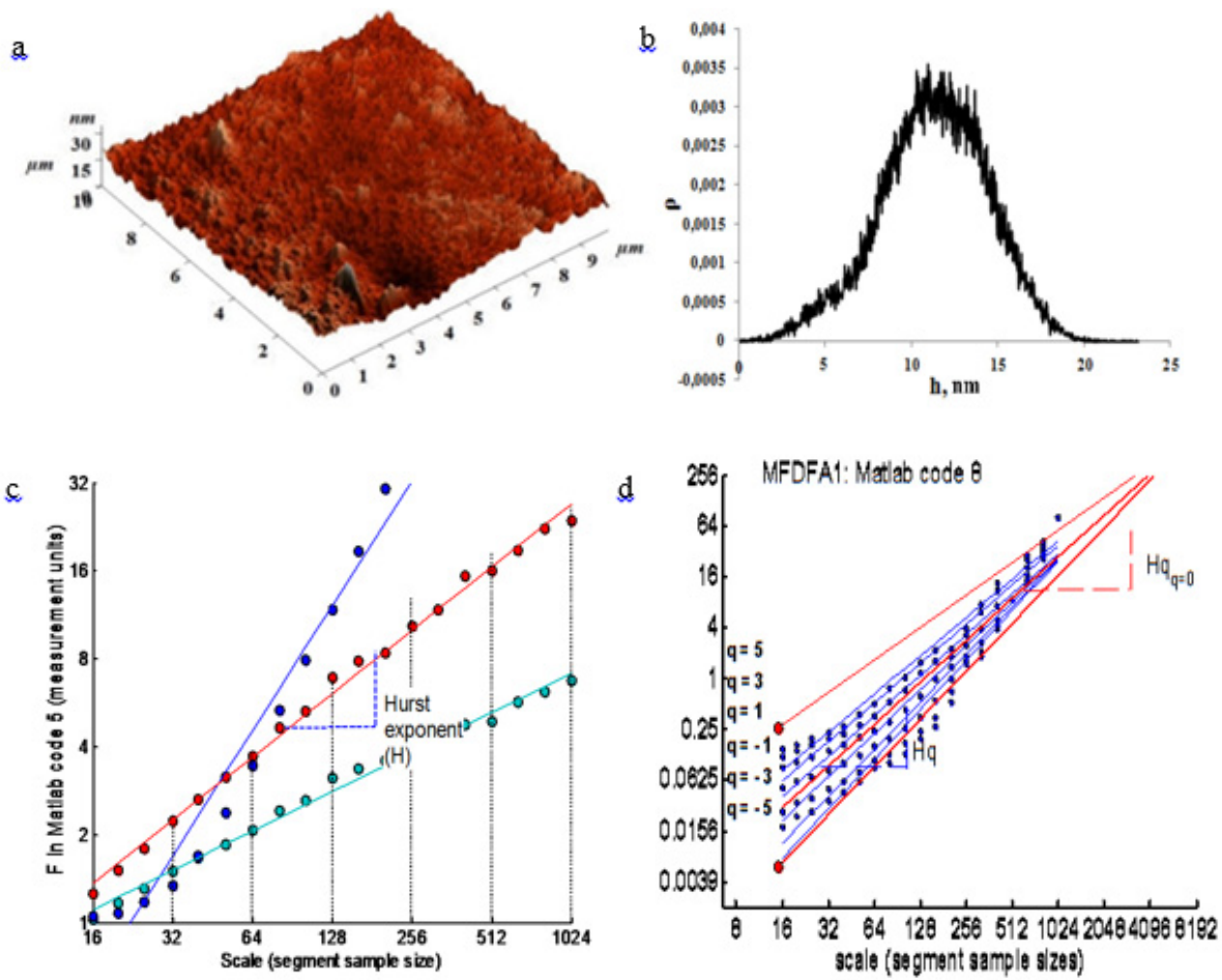

Figure 2. The Cu-containing PAN film. Technological parameters of fabrication: $\omega(\mathrm{Cu})=3.0 \mathrm{wt} . \%, \mathrm{~T}_{\mathrm{IR}}=700$ ${ }^{\circ} \mathrm{C}, \mathrm{t}_{\mathrm{IR}}=15$ minutes: a) AFM-image (three-dimensional model); b) height distribution function; c) the local Hurst exponent (monofractal series - a red line, white noise - a green line, the studied series - a blue line); d) a multifractal spectrum (a function for the local Hurst exponent estimation) 
a
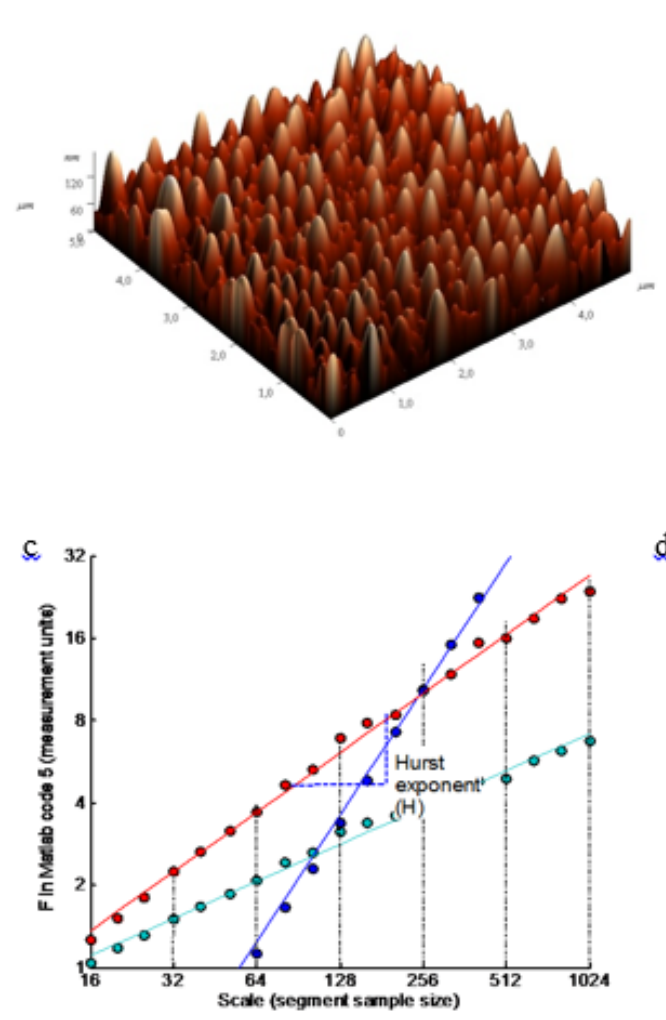

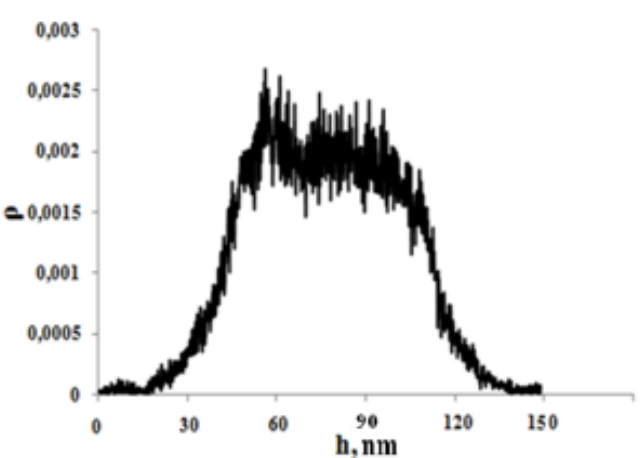

d

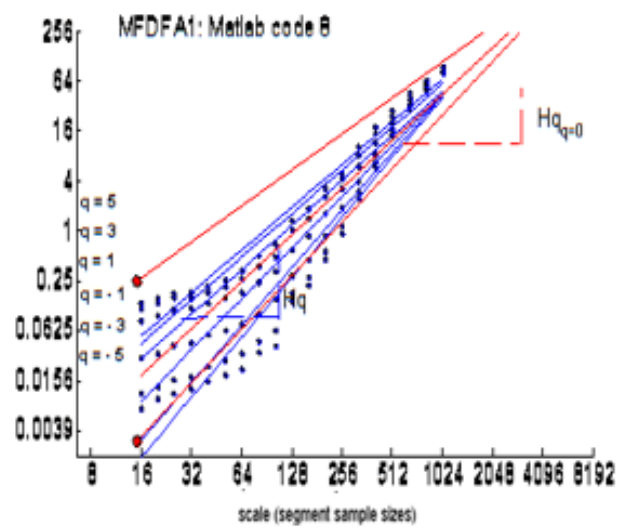

Figure 3. The Ag-containing PAN film ( $\omega(\mathrm{Ag})=1.5$ wt. $\%$, was dried at $160{ }^{\circ} \mathrm{C}$ for 30 minutes $)$ : a) AFM-image (three-dimensional model); b) height distribution function; c) the local Hurst exponent (monofractal series - a red line, white noise - a green line, the studied series - a blue line); d) a multifractal spectrum (a function for the local Hurst exponent estimation)

There is the q-order Hurst exponent $\left(H_{q}\right)$ that is one of several types of scaling exponents to parameterize the multifractal structure of time series. The typical procedure of MFDFA technique is to convert $H_{q}$ to the q-order mass exponent $\left(t_{q}\right)$ and thereafter convert $t_{q}$ to the q-order singularity exponent $\left(h_{q}\right)$ and q-order singularity dimension $\left(D_{q}\right)$ (Ihlen, 2012). The plot $h_{q}$ versus $D_{q}$ exhibits a multifractal spectrum.

The differences between all root-mean-square (RMS) deviations in multifractal spectra (Fig. 1d, Fig. 2d, Fig. 3d) converge toward each other with increase in scale. Such convergence is inevitable for multifractal variation owing to linear relationship between all $F_{q}$ and assumptions of monotonical decreasing Hurst exponent. The local convergence for local RMS deviations is used to estimate the local Hurst exponents.

The Hurst parameter values $0.5<H<1$ correspond to persistent long-range power-law correlation (Chen et al., 2009). In case a persistent time series increase (decrease) during the previous period, than Hurst exponent is closer to 1 , the tendency of the series behavior during the same period in the future is more possibly. In case a height distribution function is the input data: interpretation is to take as basic data of function of distribution on profile height that following, the Hurst parameter value is closer to 1 , the repeatability of structure over some distance is higher.

The analysis have showed that the time-temperature annealing modes increasing brings to the Hurst parameter value increasing that points to a long-range power-law correlation in structure of the studied film surface (see table 1: samples №5 and №6). However, the Hurst parameter value is high both for films with a $200 \mathrm{~nm}$ peak-to-peak that were fabricated at relatively low annealing temperatures (see table 1: samples №2-4) and for the films with a $30 \mathrm{~nm}$ peak-to-peak (see table 1: samples №5, №6).

In the first case high gas-sensitivity of the films has been detected, in the second - the low magnitude of gas-sensitivity. Here the method of film-material forming makes the difference.

The increase of modifying addictive concentration leads to formation of structures with a long-range power-law 
correlation that affects the gas-sensitivity.

The use of $\mathrm{AgNO}_{3}$ as modifying agent allows forming regular film surface (Fig.3a) that is determined by the metal-polymer structural features. The Ag-containing PAN films demonstrate the lowest magnitude of the Hurst parameter that does not inherit in gas-sensitivity.

The MF-DFA processing have revealed single and double kinks on the multifractal spectrum of the studied samples that are evident the structures of various fractal dimensions on the film surface.

Earlier we have investigated the Ag-containing PAN films using the theory of self-organization and the theory of information (Petrov et al., 2013, Makeeva et al., 2011, Lu et al., 2012). According to the work (Lu et al., 2012) the various time-temperature modes of IR-annealing and the modifying additive concentration are the technological parameters that form the unique structure of a polymer composite Ag-containing PAN film and lead to essential change of the film surface morphology. It have been established that the best gas-sensitivity shows the films with obvious self-organization processes and presence of structures with several correlation dimensions and high value of average mutual information (Vikhrov et al., 2012) or mean reciprocal information (Mursalov et al., 2000).

The MF-DFA analysis confirms the work (Petrov et al., 2013, Lu et al., 2012) conclusions. That is the adequate applications of the MF-DFA technique in the sphere of creation the functional material with defined properties.

\section{Conclusion}

Investigation of the thin metal-containing PAN film surfaces using the MF-DFA technique for assessing multifractality have been fulfilled. It is shown that peculiarity of the studied thin films is the technological modes of its fabrication owing to forming structures of different fractal dimension that is reflected in the Hurst parameter. The Hurst parameter values of the studied samples are from 0.45 to 0.76 that correspond to persistent long-range power-law correlation. It is shown the repeatability of structure over long distance is due to the high concentration of the modifying additive (3.0 wt. \%).

It is established that the gas-sensitivity values of 0.35 and more correspond to a kink in its multifractal spectrum.

We have employed this novel approach for fluctuation analysis to extract and quantify self-similarity of the structures composed of metal-organic material.

Our results suggest that multifractal analysis via MF-DFA of the AFM-images of the thin metal-containing PAN films may be used to gain an improved understanding of the sensing properties compared to traditional techniques.

\section{Acknowledgments}

The work has been supported partially by a grant of the Ministry of Education and Science of the Russian Federation a basic unit of the state task (the project No. 1509, the task No. 2014/174), which is gratefully acknowledged.

\section{References}

Al-Hadrami, I. S., Korolev, A. N., Zemtsov, L. M., Karpacheva, G. P., \& Semenistaya, T. V. (2008). Issledovanie jelektroprovodnosti IK-pirolizovannogo med'soderzhashhego poliakrilonitrila. Materialy jelektronnoj tehniki, 1, 14-17. Retrieved from http://elibrary.ru/item.asp?id=9936335

Avacheva, T. G., Bodyagin, N. V., Vikhrov, S. P., \& Mursalov, S. M. (2008). Study of self-organization in disordered materials using information theory. Semiconductors, 42(5), 499-504. http://dx.doi.org/10.1134/S1063782608050011

Bodyagin, N. V., \& Vikhrov, S. P. (1997). Dynamical criteria for reproducibility of the structure of solid materials. Technical Physics Letters, 23(10), 769-770. http://dx.doi.org/10.1134/1.1261794

Chen, X., Wong, S-Ch., \& Tse, Ch. K. (2009). Detrended fluctuation analysis of the TCP-red algorithm. Proceedings of I. J. Bifurcation and Chaos, 4237-4245. http://dx.doi.org/10.1.1.207.4596

Dawidczyk, T. J., Kong, H., \& Katz, H. E. (2013). Organic semiconductors (OSCs) for electronic chemical sensors. Handbook of Organic Materials for Optical and (Opto)electronic Devices, 577-596. http://dx.doi.org/10.1533/9780857098764.3.577

Ihlen, E. A. F. (2012). Introduction to multifractal detrended fluctuation analysis in Matlab. Frontiers in physiology, 3, article 141. http://dx.doi.org/10.3389/fphys.2012.00141

Kantelhardt, J. W. (2008). Fractal and Multifractal Time Series. Germany, Springer's Encyclopedia of 
Complexity and System Science. http://arxiv.org/abs/0804.0747

Kantelhardt, J. W., Koscielny-Bunde, E., Rego, H. H. A., Havlin, S., \& Bunde, A. (2001). Detecting long-range correlations with detrended fluctuation analysis. Physica A, 295, 441-454. http://dx.doi.org/10.1016/S0378-4371 (01) 00144-3

Kantelhardt, J. W., Zschiegner, S. A., Bunde, A., Havlin, S., Koscielny-Bunde, E., \& Stanley, H. E. (2002). Multifractal detrended fluctuation analysis of non-stationary time series. Physica A, 316, 87-114. http://dx.doi.org/10.1016/S0378-4371 (02) 01383-3

Korolev, A. N., Semenistaya, T. V., Al-Hadrami, I. S., Nazarova, T. N., \& Petrov, V. V. (2008). Issledovanie sensornyh svojstv med'soderzhashhego poliakrilonitrila. Izv. Vuzov Jelektronika, 1, 20-25. http://elibrary.ru/item.asp?id=9919005

Lange, U., Roznyatovskaya, N. V., \& Mirsky, V. M. (2008). Conducting polymers in chemical sensors and arrays. Analytica Chimica Acta, 614, 1-26. http://dx.doi.org/10.1016/j.aca.2008.02.068

Li, X., Wang, Y., Yang, X., Chen, J., Fu, H., \& Cheng, T. (2012). Conducting polymers in environmental analysis. Trends in Analytical Chemistry, 39, 163-179. http://dx.doi.org/10.1016/j.trac.2012.06.003

Lu, P., Ivanets, V. A., Semenistaya, T. V., \& Plugotarenko, N. K. (2012). Issledovanie vliyaniya strukturyi plenok serebrosoderzhaschego PAN na ih gazochuvstvitelnost $\mathrm{s}$ primeneniem teorii samoorganizatsii, teorii informatsii $\mathrm{i}$ atomno-silovoy mikroskopii. Nano- $i$ mikrosistemnaya tehnika, 5, 21-28. http://elibrary.ru/item.asp?id=17736443

Makeeva, N. A., Lu, P, Ivanets, V. A., Semenistaya, T. V., Plugotarenko, N. K., \& Korolev, A. N. (2011). Prognozirovanie velichinyi otklika na dioksid azota gazochuvstvitelnogo materiala na osnove poliakrilonitrila s pomoschyu metodov teorii samoorganizatsii. Izvestiya YuFU. Tehnicheskie nauki, 117(4), 149-156. http://izv-tn.tti.sfedu.ru/?p=11913

Movahed, M. S., Jafari, G. R., Ghasemi, F., Rahvar, S., \& Tabor, M. R. R. (2006). Multifractal detrended fluctuation analysis of sunspot time series. Journal of Statistical Mechanics: Theory and Experiment, 0602:P02003. http://dx.doi.org/10.1088/1742-5468/2006/02/P02003

Mursalov, S. M., Bodyagin, N. V., \& Vikhrov, S. P. (2000). Calculation of correlations in the surface structure of solids. Technical Physics Letters, 26(8), 668-670. http://dx.doi.org/10.1134 / 1,1307808

Oswiecimka, P., Kwapin, J., \& Drozdz, S. (2006). Wavelet versus detrended fluctuation analysis of multifractal structures. Physical Review E: Statistical, Nonlinear, and Soft Matter Physics, 74, 161-203. http://dx.doi.org/10.1103/PhysRevE.74.016103

Pavlov, A. N., \& Anishchenko, V. S. (2007). Multifractal analysis of complex signals. Physics-Uspekhi, 50(8), 819-834. http://dx.doi.org/10.3367/UFNr.0177.200708d.0859

Petrov, V. V., Plugotarenko, N. K., \& Semenistaya, T. V. (2013). Self-organization in the thin gas-sensitive Ag-containing polyacrylonitrile films. Chaotic Modeling and Simulation, 4, 609-614. http://www.cmsim.eu/papers_pdf/october_2013_papers/13_CMSIM-Journal_2013_Petrov_etal_4_609-614. pdf

Semenistaya, T. V., Petrov, V. V., \& Lu, P. (2013). Nanocomposite of Ag-polyacrylonitrile as a selective chlorine sensor. Advanced Materials Research, 804, 135-140.

Semenistaya, T. V., Petrov, V. V., Kalazhokov, Kh. Kh., Kalazhokov, Z. Kh., Karamurzov, B. S., Kushkhov, Kh. V., \& Konovalenko, S. P. (2015). Study of the properties of nanocomposite cobalt-containing IR-pyrolyzed polyacrylonitrile films. Surface Engineering and Applied Electrochemistry, 51(1), 9-17. http://dx.doi.org/10,3103 / S1068375515010147

Sokół, M., Grobelny, J., \& Turska, E. (1987). Investigation of structural changes of polyacrylonitrile on swelling. Wide-angle X-ray scattering study. Polymer, 28, 843-846. http://dx.doi.org/10.1016/0032-3861(87)90238-2

Vikhrov, S. P., Avacheva, T. G., Bodyagin, N. V., \& Grishankina, N. V. (2012). Determination of the degree of ordering of materials' structure by calculating the information-correlation characteristics. Semiconductors, 46(4), 415-421. http://dx.doi.org/10.1134 / S1063782612040240

Vikhrov, S. P., Bodyagin, N. V., Larina, T. G., \& Mursalov, S. M. (2005). Processes of growth of disordered semiconductors in the context of self-organiziation theory. Semiconductors, 39(8), 917-923 http://dx.doi.org/10.1134/1.2010685 
Wu, C. R., Salaneck, W. R., \& Ritsko, J. J. (1986). X-ray photoelectron spectroscopy of polyacrylonitrile. Synthetic Metals, 16, 147-159. http://dx.doi.org/10,1016 / 0379-6779 (86) 90107-4

Yakhmi, J. V., Saxena, V., \& Aswal, D. K. (2012). Conducting Polymer Sensors, Actuators and Field-Effect Transistors. Functional Materials, 61-110. http://dx.doi.org/10.1016/B978-0-12-385142-0.00002-7

\section{Copyrights}

Copyright for this article is retained by the author(s), with first publication rights granted to the journal.

This is an open-access article distributed under the terms and conditions of the Creative Commons Attribution license (http://creativecommons.org/licenses/by/3.0/). 